\title{
Chances of Pneumothorax and Malpositioning of Central Venous Catheters in Internal Jugular Vein Versus Subclavian Vein Routes
}

${ }^{1}$ Riffat Saeed, ${ }^{1}$ Muhammad Naveed Shahzad, ${ }^{2}$ Zia Qazi, ${ }^{3}$ Iram Qamar, ${ }^{4}$ Amna Javed, ${ }^{5}$ Arif Javed

${ }^{I}$ Department of Anesthesia, Shaikh Zayed Medical Complex, Lahore

${ }^{2}$ Department of ENT, Shaikh Zayed Medical Complex, Lahore

${ }^{3}$ Department of Anesthesia, Mayo Hospital, Lahore

${ }^{4}$ Department of Gynecology \& Obstetrics, Shaikh Zayed Medical Complex, Lahore

${ }^{5}$ Department of General Surgery, Shaikh Zayed Medical Complex, Lahore

\begin{abstract}
Introduction: Central venous catheterization (CVC) is being done all over the world. It has specific indications and should be reserved for the patient who has the potential to benefit from it. Catheter related infections are an important cause of morbidity and mortality worldwide. All complications and side effects are dependent on vascular access route. International data shows malpositioning and pneumothorax related to malpositioning to be the most common complications of central venous cannulation. However there is paucity of local data regarding which of the two, IJV or SCV routes are more prone to develop these complications. Aims \& Objectives: To compare the incidence of pneumothorax and malpositioning with internal jugular vein (IJV) and subclavian vein (SCV) routes of central venous catheters. Place and duration of study: This randomized control trial was conducted at Department of Anesthesia, Shaikh Zayed Hospital, Lahore, from 812-2014 to 7-6-2015. Material \& Methods: The non-probability purposive sampling technique was used in this study. After the approval of Hospital Ethical Committee, 290 patients were included in this study and informed consent was obtained. Demographic profile was also obtained. Patients were randomly divided in two groups by using lottery method. In Group A, CVC was inserted through internal jugular vein while in Group B, CVC was inserted through subclavian vein. During the procedure, malpositioning and pneumothorax were monitored immediately and after 36 hours and were labeled. Patients were shifted to the ward after procedure and were followed-up there. During first 36 hours, chest x-ray for placement of tip of catheter and development of pneumothorax was carried out. Chi-square was used to compare complications in both groups taking $p$ value $\leq 0.05$ as significant. Results: Malposition was found in 18 cases, (6 from IJV group and 12 from SCV group) (p-value 0.144). Pneumothorax was seen in 12 cases ( 3 from IJV and 9 from SCV group) (p-value 0.077). Conclusion: Our study results concluded that IJV showed fewer incidences of pneumothorax and malpositioning than SCV technique. However, the difference was not statistically significant.
\end{abstract}

Key words: Internal Jugular Vein: IJV, Central Venous Catheterization: CVC, Subclavian Vein: SCV, Complications.

\section{INTRODUCTION}

C entral venous catheterization is being done all over the world. It has specific indications and should be reserved for the patient who has the potential to benefit from it. ${ }^{1}$ The indications for CVC include central venous pressure monitoring, inadequate peripheral venous access, cardiopulmonary resuscitation, long term intravenous therapy (chemotherapy, hemodialysis, hyper alimentation) as an adjunct to pulmonary artery catheterization and inotropic support. ${ }^{2}$ Central venous access can be achieved by different routes, utilizing femoral, axillary, internal jugular and subclavian veins, but the route favored by most centers is the internal jugular or subclavian veins. All complications and side effects depend on vascular access route. ${ }^{3}$

Malpositioning and Pneumothorax due to malpositioning are the most common complications of passing central lines, upto $30 \%$ of all mechanical detrimental events. varying with the number of 
attempts in emergent conditions where large catheters like dialysis catheters are inserted. ${ }^{4}$ Overall complication rates range upto $15 \%$, mechanical complications reported in $19 \%$ of patients, $26 \%$ infectious complications, and $26 \%$ thrombotic complications. ${ }^{5}$ It is seen that incidence of pneumothorax varies in different studies. ${ }^{6}$

Luyt et al., conducted a randomized trial and reported that the incidence of malposition was reported to be low with IJV $(1.8 \%)$ as compared to SCV (7.4\%), however, the difference was insignificant $(p=0.07)$ and the incidence of pneumothorax was also nil (0) with IJV as compared to $\operatorname{SCV}(3.2 \%),(p=0.09){ }^{7}$

Due to the presence of conflicting international data and scarcity of our own, the research was designed to determine these complications in relation to IJV \& SCV routes in our local setting.

\section{MATERIAL AND METHODS}

Study Design: Cross sectional survey.

Setting: Department of Anesthesia, Shaikh Zayed Medical Complex, Lahore.

Duration: Six months after the approval of synopsis.

Sample Size: Sample size of 60 cases (30 in each group) is calculated in both groups with $95 \%$ confidence level, $10 \%$ margin of error, and taking expected percentage of complications in both groups i.e. $26 \%$.

Sampling Technique: Non probability consecutive sampling.

\section{Statistical analysis:}

All the data was entered and analyzed through SPSS version 20.0. The quantitative variables like age were presented as mean $\&$ standard deviation. The qualitative variable like gender, Malpositioning and pneumothorax were presented as frequency and percentages. Chi-square was used to compare complications in both groups taking $p$ value $\leq 0.05$ as significant.

\section{RESULTS}

The mean age of the patients was $45.42 \pm 15.89$ years with minimum age of 18 years and maximum age of 70 years (Table-1). In our study out of 290 cases $61.72 \%$ patients were males and $38.28 \%$ patients were females, (male to female ratio of 1.6:1) (Fig$1)$. The study results showed that malpositioning was found in $18(6.2 \%)$ patients and it was not found in $271(93.8 \%)$ patients (Table-2). In this study the pneumothorax was observed in $12(4.14 \%)$ patients whereas it was not observed in 278 (95.86\%) patients (Fig-2).

Malposition was found in 18 cases in which 6 patients were from IJV group and 12 were from SCV group, similarly malposition was not found in 272 cases in which 139 were from IJV group and 133 were from SCV group. Statistically insignificant incidence of malpositioning was found in both groups (pvalue0.144) (Table-3).

Pneumothorax was observed in 12 cases, in which 3 patients were from IJV group and 9 were from SCV group, similarly pneumothorax was not observed in 278 cases in which 142 were from IJV group and 136 were from SCV group. Statistically the difference of incidence of pneumothorax between the two groups was nonsignificant (p0.077) (Table4).

Data was stratified for age and it was noticed that in patients of age $<40$ years, malpositioning was found in 2 cases in IJV group and 6in SCV group. While in patients of age $\geq 40$ years, malpositioning was found in 4 cases in IJV group and 6 in SCV group. Statistically the difference was nonsignificant with a $p$ value $>0.05$ (Table-5). Data was stratified for age and it was noticed that in patients of age $<40$ years, the pneumothorax was observed in 1 case in IJV group and 4 in SCV group. Similarly, pneumothorax was observed in 2 cases in IJV group and 5 in SCV group. Statistically the difference was nonsignificant with $\mathrm{p}$ value $>0.05$ (Table-6).

Data was stratified for gender and malpositioning was found in 3 cases in IJV group and 5in SCV group in male participants. While in female patients, malpositioning was found in 3 cases in IJV group and 7 in SCV group. Statistically nonsignificant difference was found between the two groups with $p>0.05$ (Table-7). Data was stratified for gender and it was noticed that in male patients, the pneumothorax was observed 1 case in IJV group and 3 in SCV group. Similarly, pneumothorax was observed in 2 cases in IJV group and 6in SCV group. Statistically the difference was nonsignificant between the two groups with a $\mathrm{p}$ value $>0.05$ (Table8).

\begin{tabular}{|c|c|c|}
\hline \multirow{4}{*}{ Age (years) } & $\mathbf{N}$ & 290 \\
\cline { 2 - 3 } & Mean & 45.42 \\
\cline { 2 - 3 } & SD & 15.89 \\
\cline { 2 - 3 } & Minimum & 18.00 \\
\cline { 2 - 3 } & Maximum & 70.00 \\
\hline
\end{tabular}

Table-1: Descriptive statistics of age (years) 


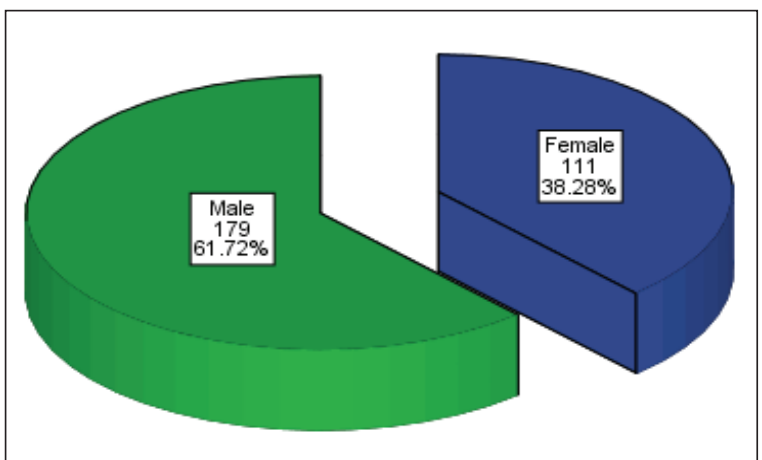

Fig-1: Percentage. distribution of gender

\begin{tabular}{|c|c|c|c|}
\hline \multicolumn{2}{|c|}{} & No. & Percent \\
\hline \multirow{3}{*}{ Malposition } & Yes & 18 & 6.2 \\
\cline { 2 - 4 } & No & 271 & 93.8 \\
\hline
\end{tabular}

Table-2: No. distribution of Malposition

\begin{tabular}{|c|c|c|c|c|}
\hline & \multicolumn{2}{|c|}{ Study Groups } & \multirow{2}{*}{ Total } \\
\hline & & IJV & SCV & \\
\hline \multirow{2}{*}{ Malposition } & Yes & 6 & 12 & 18 \\
\hline & No & 139 & 133 & 272 \\
\hline \multicolumn{2}{|l|}{ Total } & 145 & 145 & 290 \\
\hline
\end{tabular}

Table-3: Comparison of Malpositioning in both groups

\begin{tabular}{|c|c|c|c|c|}
\hline & \multicolumn{2}{|c|}{ Study Groups } & \multirow{2}{*}{ Total } \\
\hline & & IJV & SCV & \\
\hline \multirow{2}{*}{ Pneumothorax } & Yes & 3 & 9 & 12 \\
\hline & No & 142 & 136 & 278 \\
\hline \multicolumn{2}{|l|}{ Total } & 145 & 145 & 290 \\
\hline
\end{tabular}

Table-4: Comparison of Pneumothorax in both groups

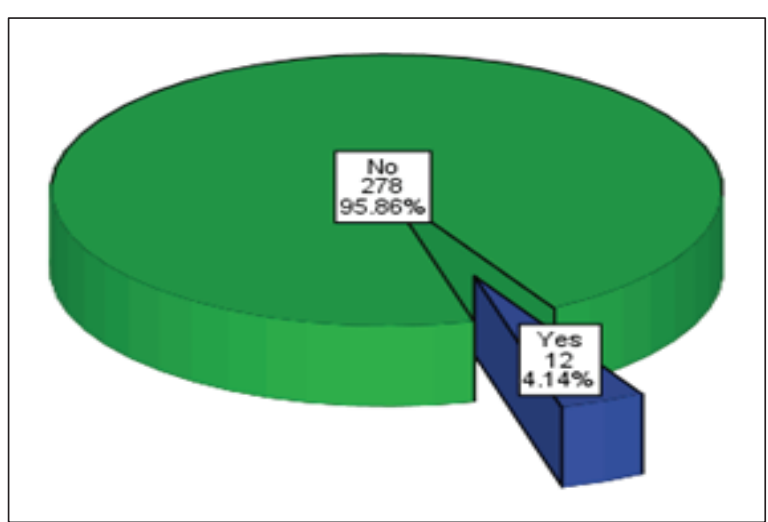

Fig-2: No. distribution of Pneumothorax

\begin{tabular}{|l|c|l|l|l|}
\hline \multirow{2}{*}{ Age } & $\begin{array}{c}\text { Mal- } \\
\text { positioning }\end{array}$ & \multicolumn{2}{|l|}{ Study Groups } & \multirow{2}{*}{ P value } \\
\cline { 3 - 4 }$<4 \mathbf{4 0}$ years & Yes & 2 & 6 & \multirow{2}{*}{0.157} \\
\cline { 2 - 4 } & No & 55 & 53 & \\
\hline \multirow{2}{*}{$\geq \mathbf{4 0}$ years } & Yes & 4 & 6 & \multirow{2}{*}{0.491} \\
\cline { 2 - 4 } & No & 84 & 80 & \\
\hline
\end{tabular}

Table-5: Comparison of malpositioning in both groups stratified by age

\begin{tabular}{|l|c|c|c|c|}
\hline \multirow{2}{*}{ Age } & \multirow{2}{*}{ Pneumothorax } & \multicolumn{2}{|l|}{ Study Groups } & \multirow{2}{*}{ Pvalue } \\
\cline { 2 - 4 } & & IJV & SCV & \\
\hline \multirow{2}{*}{$<\mathbf{4 0}$ years } & Yes & 1 & 4 & \multirow{2}{*}{0.183} \\
\cline { 2 - 4 } & No & 56 & 55 & \\
\hline \multirow{2}{*}{$\geq \mathbf{4 0}$ years } & Yes & 2 & 5 & \multirow{2}{*}{0.235} \\
\cline { 2 - 4 } & No & 86 & 81 & \\
\hline
\end{tabular}

Table-6: Comparison of Pneumothorax in both groups stratified by age

\begin{tabular}{|l|c|c|c|c|}
\hline \multirow{2}{*}{ Gender } & \multirow{2}{*}{ Malpositioning } & \multicolumn{2}{|l|}{ Study Groups } & \multirow{2}{*}{ p-value } \\
\cline { 2 - 4 } & & IJV & SCV & \\
\hline \multirow{2}{*}{ Male } & Yes & 3 & 5 & \multirow{2}{*}{0.513} \\
\cline { 2 - 4 } & No & 51 & 52 & \\
\hline \multirow{2}{*}{ Female } & Yes & 3 & 7 & \multirow{2}{*}{0.175} \\
\cline { 2 - 4 } & No & 88 & 81 & \\
\hline
\end{tabular}

Table-7: Comparison of mal-positioning in both groups stratified by gender

\begin{tabular}{|c|c|c|c|c|}
\hline \multirow{2}{*}{ Gender } & \multirow{2}{*}{ Pneumothorax } & \multicolumn{2}{|c|}{ Study Groups } & \multirow{2}{*}{ p-value } \\
\cline { 2 - 4 } Male & Yes & 1 & 3 & \multirow{2}{*}{0.335} \\
\cline { 2 - 4 } & No & 53 & 54 & \\
\hline \multirow{2}{*}{ Female } & Yes & 2 & 6 & \multirow{2}{*}{0.135} \\
\cline { 2 - 4 } & No & 89 & 82 & \multirow{2}{*}{ So } \\
\hline
\end{tabular}

Table-8: Comparison of pneumothorax in both groups stratified by gender

\section{DISCUSSION}

The choice of anatomical site of central catheter insertion should be on evidence based guidelines instead of personal preferences. The data on catheter malpositioning may have more impact on clinical decision-making. Malpositioning was reported in $14 \%$ of cases even with expert practitioners. ${ }^{10}$

In our study the IJV and SCV procedures were applied.Overall complication of malposition was found in 18(6.2\%) patients and complication of pneumothorax was observed in $12(4.14 \%)$ patients.. According to our study were did not find any significant difference between the complications (pneumothorax \& malposition) among the study groups. Some of the studies are discussed below showing the results in favor of our study. 
Sibylle Ruesch et al concluded in their study that there was lesser incidence of catheter malposition and more incidences of arterial punctures with internal jugular vein route compared with the other access. There was no difference in incidence of hemothorax, pneumothorax or vessel occlusion. ${ }^{8}$

Luyt et al., conducted a randomized trial and found that malposition was reported to be low with IJV $(1.8 \%)$ as compared to SCV $(7.4 \%$, however the difference was insignificant $(\mathrm{P}=0.07)$ as well as number of pneumothorax was also nil (0) with IJV as compared to $\operatorname{SCV}(3.2 \%, \mathrm{p} 0.09){ }^{7}$

Eisenhauer et al reported in their study that the rate of complications was $13.7 \%$. There were 286 cannulations done in subclavian vein, having 12 complications out of 13 total morbidities in the study (incidence 4.2\%), whereas in 248 internal jugular cannulations, there was only 1 case of morbidity $(0.4 \%)$. So it is recommended on the basis of these results, that internal jugular vein route should be preferred, and the subclavian route should be reserved for cases where internal jugular approach is technically difficult or for patients requiring parenteral nutrition. ${ }^{16}$

Different studies have showed results related to malposition. They have stated that jugular access was reported to have lesser catheter malposition. ${ }^{9,12,13,14,15}$

Peres et al., disagreed with the results of Luyt and Reusch studies and found that malposition was $18.97 \%$ with IJV but $33.6 \%$ with SCV which was significant (P0.01) however, pneumothorax was nil in both groups. ${ }^{9}$

McGee, et al., investigated if the use of $16 \mathrm{~cm}$ central venous catheters minimized intracardiac placements. 127 patients were assessed using either of the two routes. $16 \mathrm{~cm}$ catheters were used in 102 patients and $20 \mathrm{~cm}$ in 25 cases. In conclusion, using $16 \mathrm{~cm}$ catheters through either of the internal jugular or subclavian routes had more incidences of safe catheterizations. It was recommended to make smaller catheter use as standard practice. ${ }^{17}$

In a case series, a technique was introduced in which the site of venous puncture was at the junction of subclavian and internal jugular veins, 2 to $3 \mathrm{~cm}$ above clavicle, close to the posterior border of sternocleidomastoid. It was successful in 94\% cases, with complications (5\%) of, 6 thoracic duct cannulations, 4 arterial punctures and 2 cases of pneumothorax in a total of 600 cases. ${ }^{18}$

Non-randomized studies have reported ambiguous conclusions for complications like arterial puncture, arrhythmias, hematoma, pneumothorax or hemothorax when the internal jugular vein route is compared to the subclavian route. ${ }^{11,16,18}$

\section{CONCLUSION}

It is concluded that the incidence of malpositioning and pneumothorax is related more to the subclavian vein route as compared to the internal jugular route, however, the difference is not statistically significant.

\section{REFERENCES}

1. Celinski SA, Snafu MG. Central venous catheters. In: Irwin RS, Rippe JM, editors. Irwin and Rippe's intensive care medicine. 7TH ed. Philadelphia: Lippincott Williams \& Wilkins; 2011: p 19-37.

2. Ray BR, Mohan VK, Kashyap L, Shende D, Darlong VM, Pandey RK. Internal jugular vein cannulation: A comparison of three techniques. Journal of anaesthesiology, clinical pharmacology. 2013; 29(3):367.

3. Kumar A, Gupta K, Bhandari S, Singh R. Folding back of central venous catheter in the internal jugular vein: Methods to diagnose it at the time of insertion? Indian journal of anaesthesia. 2013; 57(1):104.

4. Marik PE, Flemmer M, Harrison W. The risk of catheter-related bloodstream infection with femoral venous catheters as compared to subclavian and internal jugular venous catheters: A systematic review of the literature and meta-analysis. Critical care medicine. 2012; 40(8):2479-85.

5. Sayed AA, Johar A, Nazir A, Qasim M. Central venous pressure line. Professional Med J. 2009; 16:44-7.

6. Rezende-Neto J, Hoffmann J, Al Mahroos M, Tien H, Hsee L, Spencer Netto F, et al. Occult pneumomediastinum in blunt chest trauma: clinical significance. Injury. 2010; 41(1):40-3.

7. Luyt D, Mathivha L, Litmanovitch M, Dance M, Brown J. Confirmation of the safety of central venous catheterisation in critically ill infants and children-the Baragwanath experience. South African Med J 1996; 86(5Suppl):603-6.

8. Ruesch S, Walder $\mathrm{B}$ and Tramèr $\mathrm{M}$. Complications of central venous catheters: Internal jugular versus subclavian access-A systematic review. Critical Care Medicine, 2002; 30(2), pp.454-460.

9. Peres P. Positioning Central Venous Catheters A Prospective Survey. Anaesthesia and Intensive Care, 1990; 18(4), pp.536-539.

10. Gladwin MT, Slonim A, Landucci DL, Gutierrez DC, Cunnion RE. Cannulation of the 
internal jugular vein: is postprocedural chest radiography always necessary? Critical care medicine. 1999; 27(9):1819-23.

11. Sznajder J, Zveibil F, Bitterman H, Weiner P and Bursztein S. Central Vein Catheterization. Failure and Complication Rates by Three Percutaneous Approaches. Survey of Anesthesiology, 1986; 30(4), p.196.

12. Barrera R, Mina B, Huang Y, Groeger JS. Acute complications of central line placement in profoundly thrombocytopenic cancer patients. Cancer. 1996; 78(9): 2025-30.

13. Kaiser CW, Koornick AR, Smith N, Soroff HS. Choice of route for central venous cannulation: Subclavian or internal jugular vein? A prospective randomized study. Journal of surgical oncology. 1981; 17(4):345-54.

14. Litmanovitch M, Hon H, Luyt D, Dance M, Mathivha L. Comparison of central venous pressure measurements in the intrathoracic and the intra-abdominal vena cava in critically ill children. Anaesthesia. 1995; 50(5):407-10.

15. Reed C, Sessler C, Glauser F, Phelan B. Central venous catheter infections: concepts and controversies. Intensive care medicine. 1995; 21(2):177-83.

16. Eisenhauer ED, Derveloy RJ, Hastings PR. Prospective evaluation of central venous pressure (CVP) catheters in a large city-county hospital. Annals of surgery. 1982; 196(5):560.

17. McGee WT, Moriarty KP. Accurate placement of central venous catheters using a $16-\mathrm{cm}$ catheter. Journal of intensive care medicine. 1996; 11(1):19-22.

18. Haapaniemi L, Slätis P. Supraclavicular catheterization of the superior vena cava. Acta Anaesthesiologica Scandinavica. 1974; 18(1):12-22.

19. Molgaard O, Nielsen M, Handberg B, Jensen J, Kjaergaard J, Juul N. Routine X-ray control of upper central venous lines: Is it necessary? Acta Anaesthesiologica Scandinavica. 2004; 48(6): 685-9.
The Authors:

Dr. Riffat Saeed

Assistant Professor,

Department of Anesthesia,

Shaikh Zayed Medical Complex, Lahore.

Dr. Muhammad Naveed Shahzad

Anesthetist,

Department of Anesthesia

Shaikh Zayed Medical Complex, Lahore.

Dr. Zia Qazi

Assistant Professor,

Department of ENT,

Shaikh Zayed Medical Complex, Lahore.

Dr. Iram Qamar

Assistant Professor,

Department of Anesthesia,

Mayo Hospital, Lahore.

Dr. Amna Javed

Assistant Professor,

Department of Gynecology \& Obstetrics, Shaikh Zayed Medical Complex, Lahore.

Dr. Arif Javed

Assistant Professor,

Department of General Surgery,

Shaikh Zayed Medical Complex, Lahore.

\section{Corresponding Author:}

Dr. Riffat Saeed

Assistant Professor,

Department of Anesthesia,

Shaikh Zayed Medical Complex, Lahore.

E-mail: zahidhnch@hotmail.com 